\title{
PREDICTORS OF MALIGNANCY IN LYMPHOCYTIC PLEURAL EFFUSIONS
}

\author{
Reshmi Sasidharan Nair1, Chellappan Sudheendra Ghosh², Kumari Indira Kalavampara Sankaran ${ }^{3}$
}

${ }^{1}$ Assistant Professor, Department of Pulmonary Medicine, GMC, Trivandrum.

2 Professor and HOD, Department of Pulmonary Medicine, SGMC and RF, Venjaramoodu.

3 Professor and HOD, Department of Pulmonary Medicine, SNIMS, Kochi.

\begin{abstract}
BACKGROUND

Commonest causes of exudative pleural effusions are synpneumonic, tuberculous and malignant. Synpneumonic effusions are usually neutrophilic in fluid cytology, while the other two are lymphocyte predominant. Elevated pleural fluid adenosine deaminase can suggest a tuberculous aetiology in clinically suspected cases. Malignant effusions need a fluid cytology positive for malignant cells to make a diagnosis. If not yielding, invasive biopsies need to be done. This study was undertaken to find out a group of variables, which can predict malignancy in lymphocytic pleural effusions.

Aim- To identify the best predictor of malignancy in lymphocytic pleural effusions.

Settings and Design- This was a cross-sectional study done in the Pulmonary Medicine Department, GMC, Trivandrum during the year 2000 .
\end{abstract}

\section{MATERIALS AND METHODS}

All exudative pleural effusions who attended the department during the period were recruited for the study after excluding empyema, synpneumonic effusions and post-traumatic effusions. A total of 133 cases were studied, 47 malignant and 86 tuberculous. The demographic characteristics, clinical features and pleural fluid characteristics were studied in all.

Statistical Analysis- Done using SPSS statistical software. Univariate analysis was done for the variables and those found significant were included in logistic regression to find the statistical significance.

\section{RESULTS}

A high positive predictive value for malignancy was noted for the presence of lymph node enlargement (71.4) and haemorrhagic pleural fluid (79.1). Many others like age $>50$ years, absence of pleural fluid loculation, Mantoux $<15 \mathrm{~mm}$, presence of clubbing, ESR $<80 \mathrm{~mm} / \mathrm{hr}$ had a high negative predictive value.

\section{CONCLUSION}

A high negative predictive value for the variables suggest that if the test for the variable is negative, it rules out the possibility of malignancy. But if positive, they need to be further evaluated to confirm the diagnosis. Further research is being currently done in the department to evaluate the usefulness of cancer ratio (serum LDH/pleural fluid ADA) in predicting malignancy.

\section{KEYWORDS}

Pleural Effusion, Lymphocytic, Malignant, Predictors.

HOW TO CITE THIS ARTICLE: Nair RS, Ghosh CS, Sankaran KIK. Predictors of malignancy in lymphocytic pleural effusions. J. Evolution Med. Dent. Sci. 2017;6(33):2697-2700, DOI: 10.14260/Jemds/2017/582

\begin{abstract}
BACKGROUND
The most common aetiologies of an exudative pleural effusion in routine clinical practice are synpneumonic, tuberculosis and malignancy. ${ }^{1}$ Around a quarter of all pleural effusions and $30 \%-70 \%$ of exudative pleural effusions in a hospital setting are secondary to cancer as per the literature. ${ }^{2}$ Malignant pleural effusion may be associated with both primary and metastatic malignancies of the pleura; $7 \%-15 \%$ of malignant effusions are from an unknown primary. The commonest primary malignancies associated with secondaries in pleura are lung, breast, lymphomas, gastrointestinal and genitourinary tumours. Presence of

Financial or Other, Competing Interest: None.

Submission 02-04-2017, Peer Review 16-04-2017,

Acceptance 18-04-2017, Published 24-04-2017.

Corresponding Author:

Reshmi Sasidharan Nair,

Assistant Professor,

Department of Pulmonary Medicine,

malignant pleural effusion defines an advanced stage of malignancy for the patient and has a poor prognosis. The mean survival is only 3 to 12 months in such patients. ${ }^{3}$ The usual initial investigations done on pleural fluid are biochemical (Protein, sugar, LDH, ADA), microbiological (AFB, Gram stain and culture) and cytological (TC, DC and cytology). A predominantly neutrophilic effusion favours a synpneumonic origin and a raised ADA (Adenosine Deaminase) level is highly suggestive of tuberculous aetiology.1,4 There are no such tests to predict malignant aetiology. Cytological examination of pleural fluid has a low yield of malignancy (60\%) and pleural biopsy is invasive, whether open or thoracoscopic. Tumour marker assays can be done, but these are expensive and not routinely available in all centres. ${ }^{5}$ This study evaluated a group of variables including demographic features, clinical and pleural fluid characteristics to identify the best predictor of malignancy from among lymphocytic effusions.
\end{abstract}

GMC, Trivandrum.

E-mail: reshmisathish@rediffmail.com

DOI: $10.14260 /$ jemds $/ 2017 / 582$

\section{MATERIALS AND METHODS}

This was a cross-sectional study done in the Pulmonary Medicine Department of Government Medical College, 
Trivandrum, on 133 cases of lymphocytic pleural effusions during the year 2000. Samples were taken purely based on feasibility. All pleural effusion cases attending the department during the one year period and who satisfied the inclusion criteria were recruited for the study. Exudative pleural effusions of synpneumonic origin, empyemas and post-traumatic effusions were excluded from the study. Ethical clearance was taken from the Institutional Ethics Committee. The cases were grouped as definite malignant or definite tuberculous, if the aetiology was proved by cytology/histopathology or microbiology/histopathology respectively. In those with high clinical suspicion of tuberculosis, but no objective evidence, anti-tuberculous treatment was started empirically and the patients were followed up for three months. If improving, they were grouped as tuberculous. If not they were further evaluated to come to a definite diagnosis. The variables analysed were age, sex, smoking index, clubbing, lymph node enlargement, fluid loculation, ESR, Mantoux, haemorrhagic pleural fluid and massive pleural effusion. Statistical analysis was done using SPSS software. Sensitivity and specificity of the variables to detect malignancy were calculated. Those found significant in univariate analysis were included in logistic regression and statistical significance calculated.

\section{RESULTS}

133 patients were included in the study; 86 were tuberculous and 47 were malignant. The baseline characteristics of the two groups are summarised in Table 1.

\begin{tabular}{|c|c|c|c|}
\hline Variable & $\begin{array}{l}\text { Tuberculous } \\
(\mathrm{N}=\mathbf{8 6})\end{array}$ & $\begin{array}{c}\text { Malignant } \\
(\mathrm{N}=47)\end{array}$ & P value \\
\hline \multirow{2}{*}{$\begin{array}{c}\text { Age }<50 \\
>50\end{array}$} & 58 & 14 & \multirow{2}{*}{0.00005} \\
\hline & 28 & 33 & \\
\hline Male: Female & $3.5: 1$ & $1.6: 1$ & 0.068 \\
\hline $\begin{array}{c}\text { Smoking Index } \\
<800\end{array}$ & 76 & 36 & \multirow[t]{2}{*}{0.08612} \\
\hline$>800$ & 10 & 11 & \\
\hline Clubbing & $19(22.1 \%)$ & $19(40.4 \%)$ & 0.029 \\
\hline $\begin{array}{l}\text { Lymph Node } \\
\text { Enlargement }\end{array}$ & $6(7 \%)$ & $15(31.9 \%)$ & 0.00032 \\
\hline \multirow{2}{*}{$\begin{array}{c}\text { ESR }<80 \\
\quad>80\end{array}$} & 58 & 37 & \multirow{2}{*}{0.22838} \\
\hline & 28 & 10 & \\
\hline \multirow{2}{*}{$\begin{array}{l}\text { Mantoux } \\
<15 \mathrm{~mm} \\
>15 \mathrm{~mm}\end{array}$} & 54 & 44 & \multirow[b]{2}{*}{0.00007} \\
\hline & 32 & 3 & \\
\hline $\begin{array}{l}\text { Haemorrhagic } \\
\text { Fluid }\end{array}$ & $9(10.5 \%)$ & $34(72.3 \%)$ & 0.000 \\
\hline $\begin{array}{l}\text { No Loculation of } \\
\text { Fluid }\end{array}$ & $64(74.4 \%)$ & $41(87.2 \%)$ & 0.119 \\
\hline Massive Effusion & $14(16.3 \%)$ & $23(48.9 \%)$ & 0.0001 \\
\hline
\end{tabular}

Table 2 summarises the sensitivity, specificity and predictive value of important variables in making a diagnosis of malignancy in pleural effusion; $10.5 \%$ of tuberculous pleural effusions had haemorrhagic pleural fluid, whereas $27.7 \%$ of malignant effusions had straw coloured pleural fluid. Pleural fluid cytology was positive for malignant cells in $59.5 \%$ of malignant effusions. The main aetiology identified for malignant pleural effusion was adenocarcinoma of lung $(44.7 \%)$. The histopathological distribution of malignant effusion are shown in Figure 1. The pleural fluid cytology showed presence of mesothelial cells in four cases. All of them turned out to be malignant. None of the tuberculous group had mesothelial cells in fluid cytology.

\begin{tabular}{|c|c|c|c|c|}
\hline Variable & Sensitivity & Specificity & PPV $^{*}$ & NPV $\dagger$ \\
\hline Age > 50 Years & 70.2 & 67.4 & 54.1 & 80.6 \\
\hline Male Sex & 61.7 & 22.1 & 30.2 & 51.4 \\
\hline $\begin{array}{c}\text { Smoking } \\
\text { Index > 800 }\end{array}$ & 23.4 & 88.4 & 52.4 & 67.9 \\
\hline Clubbing & 40.4 & 77.9 & 50 & 70.5 \\
\hline $\begin{array}{c}\text { Lymph Node } \\
\text { Enlargement }\end{array}$ & 31.9 & 93 & 71.4 & 71.4 \\
\hline $\begin{array}{c}\text { Absence of } \\
\text { Loculation }\end{array}$ & 87.2 & 25.6 & 39 & 78.6 \\
\hline ESR < 80 mm & 78.7 & 32.6 & 38.9 & 73.7 \\
\hline $\begin{array}{c}\text { Mantoux < 15 } \\
\text { mm }\end{array}$ & 93.6 & 37.2 & 44.9 & 91.4 \\
\hline $\begin{array}{c}\text { Haemorrhagic } \\
\text { Pleural Fluid }\end{array}$ & 72.3 & 89.5 & 79.1 & 85.6 \\
\hline $\begin{array}{c}\text { Massive } \\
\text { Effusion }\end{array}$ & 48.9 & 83.7 & 62.2 & 75 \\
\hline \multicolumn{4}{|c|}{ Table 2. Sensitivity, Specificity, } \\
\hline \multicolumn{4}{|c|}{ Predictive Values of the Variables } \\
\hline
\end{tabular}

*Positive predictive value

†Negative predictive value

Clinically important variables and those which showed statistical significance in univariate analysis were included in multivariate analysis. The adjusted Odds ratio and statistical significance obtained by logistic regression are shown in Table 3.

\begin{tabular}{|c|c|c|}
\hline Variable & P value & $\begin{array}{c}\text { OR (Adjusted by } \\
\text { Logistic } \\
\text { Regression) }\end{array}$ \\
\hline Age > 50 Years & 0.0557 & 4.0054 \\
\hline Male Sex & 0.0091 & 0.0989 \\
\hline $\begin{array}{c}\text { Smoking Index }> \\
800\end{array}$ & 0.1624 & 3.3595 \\
\hline Clubbing & 0.5690 & 1.5449 \\
\hline $\begin{array}{c}\text { Lymph Node } \\
\text { Enlargement }\end{array}$ & 0.0510 & 6.1743 \\
\hline $\begin{array}{c}\text { Absence of } \\
\text { Loculation }\end{array}$ & 0.9875 & 1.0133 \\
\hline ESR < 80 mm & 0.5254 & 0.6237 \\
\hline Mantoux < 15 mm & 0.0059 & 21.3923 \\
\hline $\begin{array}{c}\text { Haemorrhagic } \\
\text { Pleural Fluid }\end{array}$ & 0.0000 & 40.4341 \\
\hline Massive Effusion & 0.0054 & 10.1219 \\
\hline \multicolumn{2}{|c|}{ Table 3. Results of Multivariate } \\
Analysis (Logistic Regression) \\
\hline \multicolumn{2}{|c|}{} \\
\hline
\end{tabular}




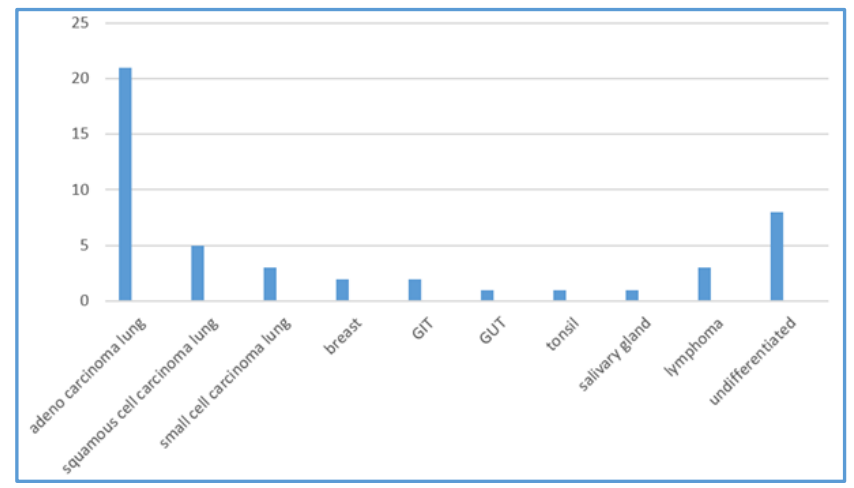

Figure 1. Distribution of Aetiology of Malignant Effusion

\section{DISCUSSION}

The study showed a high positive predictive value for malignancy for the presence of lymph node enlargement (71.4) and haemorrhagic pleural fluid (79.1). Many other clinically significant variables showed a high negative predictive value. Thus, if the test for the variable is negative, it rules out the possibility of malignancy. But if positive, it may require further evaluation to confirm the diagnosis.

The main differential diagnosis of a lymphocytic pleural effusion are tuberculosis and malignancy. Though pleural fluid analysis helps identify the cause, it often becomes difficult in a percentage of cases. This often necessitates invasive procedures like pleural biopsy- blind or thoracoscopic and use of tumour marker assays for making a definite diagnosis.1,4,5 These are not available in all centres. If we can find out a few variables which can reasonably predict the occurrence of malignancy, it will be of great use for the practising physicians. Hence, the relevance of the study. Different scoring systems have been put forward by many authors that help differentiate tuberculous and malignant aetiologies of pleural effusion. ${ }^{6}$

Recent studies by Verma et al have shown the use of a cancer ratio and cancer ratio plus for predicting malignancy among lymphocytic effusions.7,8 At a cut-off level of $>20$, the cancer ratio showed a sensitivity of $95 \%$ and a specificity of $85 \%$ in diagnosing malignancy in this study. ${ }^{8}$ Research is currently planned in our hospital to find out the best cut-off value of cancer ratio (serum $\mathrm{LDH} /$ pleural fluid ADA), which can identify malignancy as the cause of lymphocytic pleural effusion. Since both the investigations under study are done routinely as part of the initial evaluation of effusions, the result of the study will be of great help in planning further confirmative tests for diagnosing malignancy in suspected cases. Cancer ratio plus is cancer ratio/the lymphocyte count of pleural fluid. Combining the cancer ratio with the lymphocyte count of the pleural fluid, the cancer ratio plus at a value of $>30$ improved the sensitivity and specificity of distinguishing malignant from tuberculous pleural effusions to $97 \%$ and $94 \%$ respectively. ${ }^{8}$

Our study had a positive yield in pleural fluid cytology in $59.5 \%$ cases. The commonest histology identified was adenocarcinoma of the lung (44.7\%). The study by Ong et al showed a positive yield for initial cytology of $48.5 \%$. This improved with repeated cytology examinations. The same study shows the commonest malignancy as bronchogenic carcinoma in $51.5 \%$ cases. ${ }^{9}$ Similar results were observed by Bhattacharya et al also and these are comparable with our results. ${ }^{10}$
A decision tree to differentiate between tuberculous and malignant pleural effusions has been put forward by Porcel et al in 2008. In their study, they have considered variables like clinical parameters, eg: age, presence of fever, etc.; radiological appearance of effusion and also pleural fluid parameters (biochemical, cytological) to come to a scoring system which can predict the aetiology of malignancy. ${ }^{11}$

A CT scoring system has been derived by Porcel et al in distinguishing between benign and malignant pleural effusions. Pleural thickening or nodule $\geq 1 \mathrm{~cm}$, lung mass $\geq 1$ $\mathrm{cm}$, abdominal mass, liver metastasis, absence of pleural loculation, pericardial effusion or cardiomegaly all were positively associated with a malignant aetiology. The scoring was done based on these variables. ${ }^{12}$

Tumour marker study has been projected as one of the investigations to be done in pleural fluid to make a diagnosis of malignancy. This is as yet not available in most of the centres. Moreover, even the pleural disease guidelines by British Thoracic Society 2010 do not advocate the use of tumour marker study as a routine in all suspected malignant effusions. Antonangelo et al in their study conclude that tumour marker evaluation can be done in pleural fluid of patients with inconclusive cytology, having a high pre-test chance of malignancy or a history of cancer. ${ }^{13}$

Taking all together a combination of clinical, radiological and pleural fluid parameters can help predict malignancy in a large percentage of patients, thus avoiding the invasive investigations of pleural biopsy- either percutaneously or through thoracoscope. We made a humble attempt to detect the usefulness of some of these variables in our study. Further research incorporating newer and simpler investigations may be undertaken to help predict malignancy as the aetiology of exudative pleural effusions. This may help the practising physicians to diagnose a case without much delay, especially in a developing country like ours.

\section{CONCLUSION}

A high negative predictive value for the variables suggest that if the test for the variable is negative, it rules out the possibility of malignancy. But if positive, they need to be further evaluated to confirm the diagnosis. Further research is being currently done in the department to evaluate the usefulness of cancer ratio (serum LDH/pleural fluid ADA) in predicting malignancy.

\section{ACKNOWLEDGEMENTS}

I sincerely acknowledge the help given by Dr. Kumari Indira K.S, in doing the statistical analysis of the study.

\section{REFERENCES}

[1] Light RW. Diagnostic principles in pleural disease. Eur Respir J 1997;10(2):476-81.

[2] Light RW. Management of pleural effusions. J Formos Med Assoc 2000;99(7):523-31.

[3] Roberts ME, Neville E, Berrisford RG, et al. Management of malignant pleural effusion: British thoracic society pleural disease guideline 2010. Thorax 2010;65(Suppl 2):32-40. 
[4] Porcel-Pérez JM, Soto VM, Serrano EA, et al. Cuttoff values of biochemical tests on pleural fluid: their usefulness in differential diagnosis of 1,040 patients with pleural effusion. An Med Interna 2004;21(3): 113-7.

[5] Kuan-Yuan C, Po-Hao F, Chih-Cheng C, et al. Novel biomarker analysis of pleural effusion enhances differentiation of tuberculous from malignant pleural effusion. Int J Gen Med 2016;9:183-9.

[6] Porcel JM, Vives M. Differentiating tuberculous from malignant pleural effusions: a scoring model. Med Sci Monit 2003;9(5):CR175-80.

[7] Verma A, Abisheganaden J, Light RW. Identifying malignant pleural effusion by a cancer ratio (serum LDH: pleural fluid ADA ratio). Lung 2016;194:147-53.

[8] Verma A, Dagaonkar RS, Marshall D, et al. Differentiating malignant from tubercular pleural effusion by cancer ratio plus (cancer ratio: pleural lymphocyte count). Canadian Respiratory Journal Article ID 7348239, 2016;2016:6.
[9] Ong KC, Indumathi V, Poh WT, et al. The diagnostic yield of pleural fluid cytology in malignant pleural effusions. Singapore Med J 2000;41(1):19-23.

[10] Bhattacharya S, Bairagya TD, Das A, et al. Closed pleural biopsy is still useful in the evaluation of malignant pleural effusion. J Lab Physicians 2012;4(1):35-8.

[11] Porcel JM, Alemán C, Bielsa S, et al. A decision tree for differentiating tuberculous from malignant pleural effusions. Respir Med 2008;102(8):1159-64.

[12] Porcel JM, Pardina M, Bielsa S, et al. Derivation and validation of a CT scan scoring system for discriminating malignant from benign pleural effusions. Chest 2015;147(2):513-9.

[13] Antonangelo L, Sales RK, Corá AP, et al. Pleural fluid tumour markers in malignant pleural effusion with inconclusive cytologic results. Curr Oncol 2015;22(5):e336-41. 